\title{
36. PRELIMINARY ORGANIC GEOCHEMICAL ANALYSES OF THE SITE 217 CORE SAMPLES IN THE BENGAL BASIN, DSDP LEG $22^{1}$
}

\author{
Bernd R. Simoneit and A. L. Burlingame, Space Sciences Laboratory, University of California, Berkeley, California
}

\begin{abstract}
Four core samples from Site 217 were extracted, and the solvent soluble organic matter was characterized by GC (gas chromatography) and GC/MS (gas chromatography/mass spectrometry). The samples range in age from the Quaternary to the Upper Cretaceous and contain only traces of organic carbon. The normal alkanes are the major homologous series present in all the samples. They do not exhibit a carbon number preference. Unresolved cyclic and aromatic compounds comprise the bulk of the extracts. The Quaternary sample may be contaminated by drill pipe joint grease. The other samples appear to be matured sediments.
\end{abstract}

\section{INTRODUCTION}

The samples discussed herein were taken from Site 217, situated on the northern end of Ninetyeast Ridge $\left(8^{\circ} 55.6^{\prime} \mathrm{N}, 90^{\circ} 32.3^{\prime} \mathrm{E}\right)$ in 3020 meters of water. The stratigraphy at this site is comprised predominantly of calcareous ooze and chalk as detailed by von der Borch, Sclater, et al. (1971). All the samples are low in organic carbon content (average about $0.1 \%$ ). The details of each sample are given in Table 1.

\section{EXPERIMENTAL}

Analyses using GC/MS were carried out on a modified Varian MAT model $311 \mathrm{GC} / \mathrm{MS}$ linked on-line to an XDS Sigma 2 computer (Smith et al., 1971). The column conditions used in the GC and GC/MS analyses are cited in the respective figure legends, and the mass spectrometric and computer operating parameters are analogous to those reported by Smith et al. (1971). Certain mass spectra from the various GC/MS analyses were identified by using a compound classifier (Smith, 1972; Chang et al., in preparation).

Gas chromatographic analyses were carried out using a Perkin-Elmer model 900 gas chromatograph fitted with a flame ionization detector and operating under the conditions stated in the respective figure legends.

All solvents used, e.g., toluene, benzene, methanol, and $n$-heptane were Mallinckrodt nanograde quality. The toluene, benzene, and methanol were redistilled in an all-glass apparatus prior to use.

The samples were dried under vacuum $\left(60^{\circ} \mathrm{C}\right.$ and $25 \mathrm{~cm}$ $\mathrm{Hg}$ pressure) and then extracted in a sealed ball mill jar with benzene or toluene and methanol solvent mixture $(3: 1)$ according to the method of Rittenberg et al. (1963). After

\footnotetext{
${ }^{1}$ Research supported by the Oceanographic Section, National Science Foundation, NSF Grant GA-24214.
}

filtration through a fine-glass frit, the extracts were concentrated on a rotary evaporator (bath at $30-40^{\circ} \mathrm{C}$ ) and then repartitioned into a heptane-diethyl-ether-soluble fraction and a toluené or benzene-methanol-soluble fraction. The heptane-soluble fraction of Sample 217-1-3, 0-20 cm, was subjected for further separation using silica gel chromatography. A $15 \mathrm{~mm} \times 15 \mathrm{~cm}$ glass column was packed with $10 \mathrm{~g}$ conditioned $\mathrm{SiO}_{2}$ (washed with methanol, dried at $100^{\circ} \mathrm{C}$ overnight, and conditioned with heptane) and the sample eluted into 13 fractions. Each cut was analyzed by GC and similar fractions were combined.

\section{RESULTS}

The extraction yields for the Site 217 preliminary analysis are given in Table 1. The gas chromatographic traces for the total extract fractions are shown in Figure 1. Each extract is a complex unresolved mixture. The total fractions were then partitioned between heptane and benzene and methanol (3:1). Most of each fraction was soluble in heptane (cf. Table 1) which is unlike previous results from other DSDP samples (Simoneit and Burlingame, 1972; in press a). The GC traces of these fractions are shown in Figures 2 through 5 . The total fractions were also subjected to GC/MS analysis, and the salient features of those data are shown in Figures 6, 7, and 8. The GC/MS results for the total extracts are summarized in Table 2.

The predominant components in all four samples are normal alkanes. The series $\mathrm{C}_{n} \mathrm{H}_{2 n+2}$ ranges from $n=13$ to 29 , with a maximum at $n=17$ and essentially no carbon number preference for Sample 217-1-3, 0-20 cm. The $n$-alkanes amount to $6 \mathrm{ppm}$ of the dry weight for this sample. It should be noted that total ion current suppression occurs in these capillary GC/MS analyses when a large unresolved hump is injected. For example, in the data for Sample 217-1-3 (cf. Figure 6a) the scans 120-170 are detuned, resulting in the minimum observed. The normal paraffins, $\mathrm{C}_{n} \mathrm{H}_{2 n+2}$, in Sample 217-6-5, 10-30 cm, are also equivalent to about $6 \mathrm{ppm}$ and range from $n=14$ to 34 , with a maximum at $n=24$ and essentially no carbon 
TABLE 1

Sample Descriptions and Extract Yields, Site 217

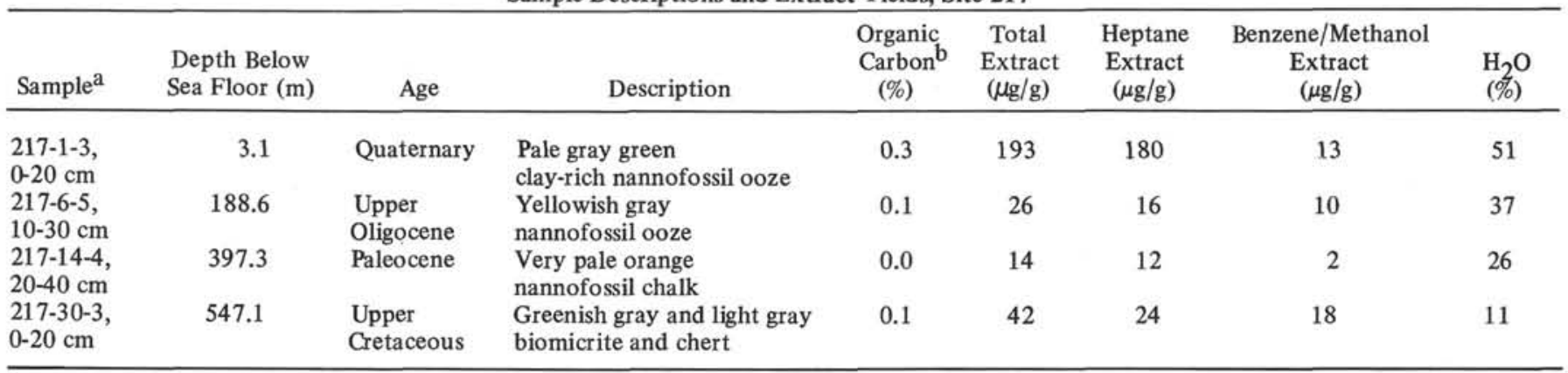

${ }^{\text {a Location }} 8^{\circ} 55.6^{\prime} \mathrm{N}, 90^{\circ} 32.3^{\prime} \mathrm{E}$, water depth $3020 \mathrm{~m}$.

bata provided by G. Bode, DSDP staff.

number preference. Sample 217-14-4, 20-40 cm, has a normal alkane distribution rnaging from $n=17$ to 33 for $\mathrm{C}_{n} \mathrm{H}_{2 n+2}$, with a maximum at $n=22$ and no carbon number preference. The alkanes account for approximately $4 \mathrm{ppm}$ of the dry sample. The series $\mathrm{C}_{n} \mathrm{H}_{2 n+2}$ ranges from $n=17$ to 35 , with a maximum at $n=22$ and again no carbon number preference in Sample 217-30-3, 0-20 cm. The $n$-alkanes amount to approximately $8 \mathrm{ppm}$ of the dry weight of this sample.

Possible contaminants from core tube material, mainly the compound dioctyl 2,3-dimethylsuccinate (Simoneit et al., 1973; Simoneit and Burlingame, in press (b), were found in all of the samples. Phthalate esters were detected in two samples (cf. Figures $6 \mathrm{~d}$ and $\mathrm{f}$ ). The Cretaceous sample (217-30-3) had a suite of unknown compounds of short GC retention times (cf. Figures 7d and 8a,b) and two peaks probably due to dipentylbenzene (Structure I). The scan 112 spectrum (Figure 7c) fits the fragmentation pattern of probably the ortho isomer of Structure I. The compound classifier matched the spectrum to an alkylbenzene. The scan 88 spectrun (Figure $8 \mathrm{~b}$ ) is a mixture of a dipentylbenzene and an unknown of molecular weight 220.

The recombined extract fractions from Sample 217-1-3, $0-20 \mathrm{~cm}$, were subjected to liquid chromatography on silica gel. The fraction yields and descriptions are listed in Table 3. Representative GC traces for this separation are found in Figure 9. Fraction 1 (cf. Figure 9a) closely resembles the initial heptane extract. Fractions 2 through 4 consist of a highly unresolved mixture of cyclic and aromatic hydrocarbons (cf. Figure 9b). Fractions 5 through 11 have the same unresolved GC traces as is the case for fractions 2 through 4. Fractions 12 and 13 consist of the more polar compounds. A GC/MS analysis of this cut was carried out. The major peaks are phthalate esters and dioctyl 2,3-dimethylsuccinate.

\section{DISCUSSION AND CONCLUSION}

The distribution histograms for the $n$-alkanes in these samples are shown in Figure 10. No carbon number preference is evident. The Quaternary sample has a maximum at $\mathrm{C}_{17}$, the Oligocene sample at $\mathrm{C}_{24}$, the Paleocene at $\mathrm{C}_{22}$, and the Cretaceous is bimodal with maxima at $\mathrm{C}_{22}$ and $C_{27}$. These alkane distributions indicate matured sediments (Bray and Evans, 1961). This distribution for the
Quaternary sediment seems peculiar, especially since the GC trace closely resembles that for drill pipe joint grease (Simoneit et al., 1972). In view of the low extract yields, contamination by drilling oils must be considered. Samples $217-14-4,20-40 \mathrm{~cm}$, and $217-30-3,0-20 \mathrm{~cm}$, exhibit a predominance of the $\mathrm{C}_{22} n$-alkane.Schenck(1969) observed this predominance in a large number of terrestrial sediments ranging in age from Miocene to Permian. Such a predominance has not been observed in crude oils (Schenck, 1969).

The contaminants such as phthalate esters and dioctyl 2,3-dimethylsuccinate were minor in all samples, indicating that the bulk of the solvent-soluble organic matter is indigenous to the sediments. The anomaly in the case of the Quaternary sample may be due to drilling lubricants or possibly petroliferous sediments of terrigenous origin eroded and brought in by the Ganges River system.

\section{ACKNOWLEDGMENTS}

We thank Mrs. Esther Roitman for technical assistance and Dr. Robert E. Cox for GC/MS analyses. The financial support from the Oceanography Section of the National Science Foundation (NSF Grant GA-24214) is gratefully acknowledged.

\section{REFERENCES}

Bray, E. E. and Evans, E. D., 1961. Distribution of $n$-paraffins as a clue to recognition of source beds: Geochim. Cosmochim. Acta, v. 22, p. 1 .

Chang, J. J., Walls, F. C., Smith, D. H., Simoneit, B. R., and Burlingame, A. L., in preparation. The LOGOS compound classifier for background corrected low resolution mass spectral data: Anal. Chem.

Rittenberg, S. C., Emery, K. O., Hülsemann, J., Degens, E. T., Fay, R. C., Reuter, J. H., Grady, J. R., Richardson, S. H., and Bray, E.E., 1963. Biogeochemistry of sediments in experimental Mohole: J. Sediment. Petrol., v. 33 , p. 140 .

Schenck, P. A., 1969. The predominance of the $\mathrm{C}_{22}$ $n$-alkane in rock extracts. In Advances in organic geochemistry, 1968: Schenck, P. A. and Havenaar, I. (Eds.), Braunschweig (Pergamon-Vieweg), p. 261.

Simoneit, B. R. and Burlingame, A. L., 1972. Preliminary organic analyses of the Deep Sea Drilling Project (JOIDES) cores, legs V-IX. In Advances in organic geochemistry 1971: von Gaertner, H. R. and Wehner, H. (Eds.), Braunschweig (Pergamon-Vieweg), p. 189. 

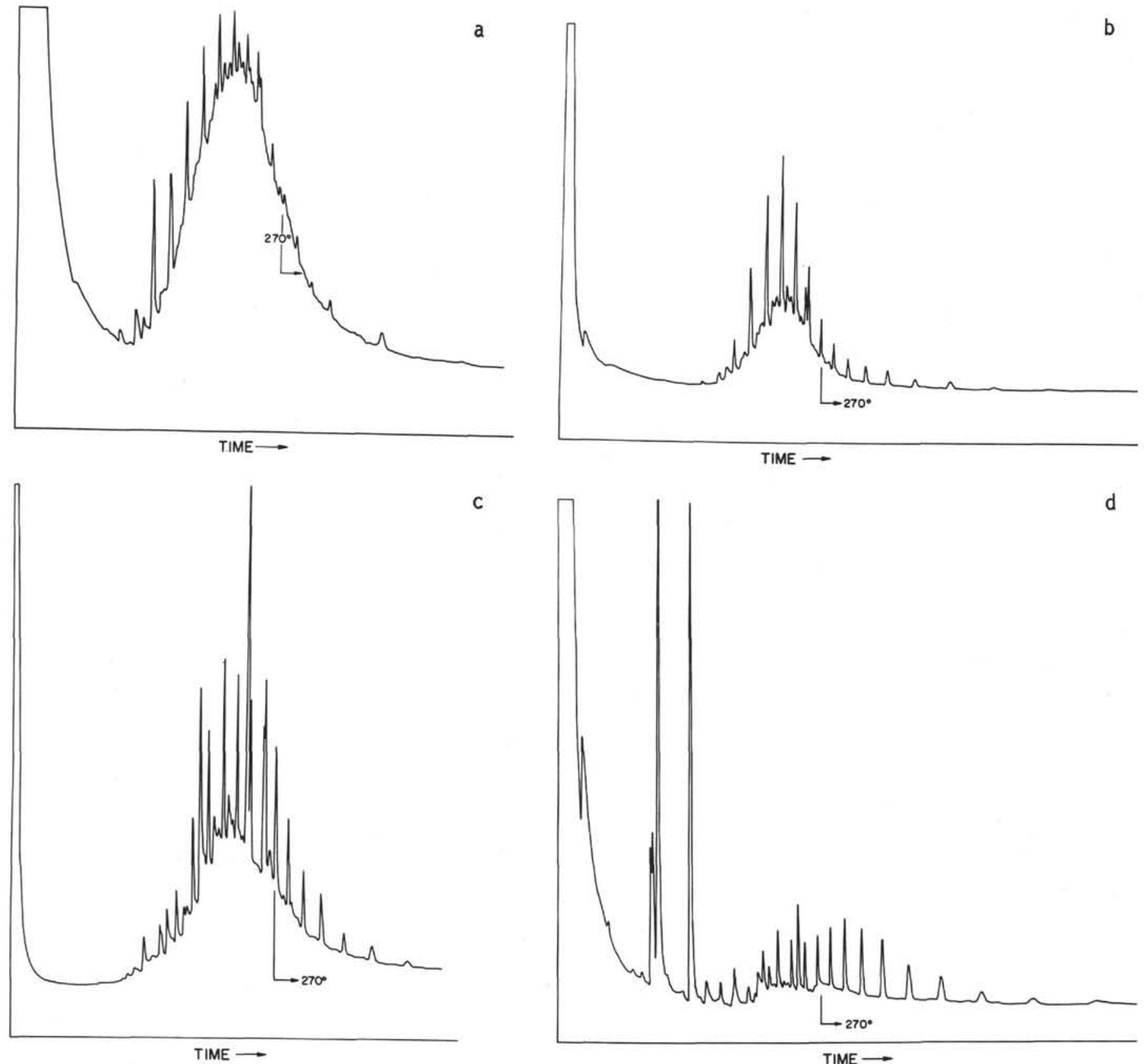

Figure 1. Gas chromatograms of the total extract fractions from core samples: (a) $217-1-3,0-20 \mathrm{~cm}$; (b) 217-6-5, 10-30 cm; (c) 217-14-4, 20-40 cm; (d) 217-30-3, 0-20 cm. (GC conditions: $10 \mathrm{ft} \times 1 / 8$ in. stainless steel column, packed with $3 \%$ OV-1 on 100-120 mesh Gaschrom Q, programmed from $100-270^{\circ} \mathrm{C}$ at $6^{\circ} / \mathrm{min}$, and using He carrier gas at $40 \mathrm{ml} / \mathrm{min}$ ).

1973 in press (a). Comparative compositional studies of organic matter in the DSDP (JOIDES) cores, legs 5-15: Am. Assoc. Petrol. Geol. Bull.

in press (b). Preliminary organic analyses of DSDP cores, legs 12 and 13. In Winterer, E. L., Ewing, J. et al., Initial Reports of the Deep Sea Drilling Project, Volume XVII: Washington (U.S. Government Printing Office).

Simoneit, B. R., Scott, E. S., Howells, W. G., and Burlingame, A. L., 1972. Preliminary organic analyses of the Deep Sea Drilling Project cores from leg 11. In Hollister, C. D., Ewing, J. I., et al. Initial Reports of the
Deep Sea Drilling Project, Volume XI: Washington (U. S. Government Printing Office), p. 1013.

Simoneit, B. R., Scott, E. S., and Burlingame, A. L., 1973. Preliminary organic analyses of DSDP cores, Leg 14, Atlantic Ocean. In van Andel, T. H., Heath, G. R., et al., Initial Reports of the Deep Sea Drilling Project, Volume XVI: Washington (U. S. Government Printing Office), p. 575 .

Smith, D. H., 1972. A compound classifier based on computer analysis of low resolution mass spectral data. Geochemical and environmental applications: Anal. Chem., v. 44, p. 536. 

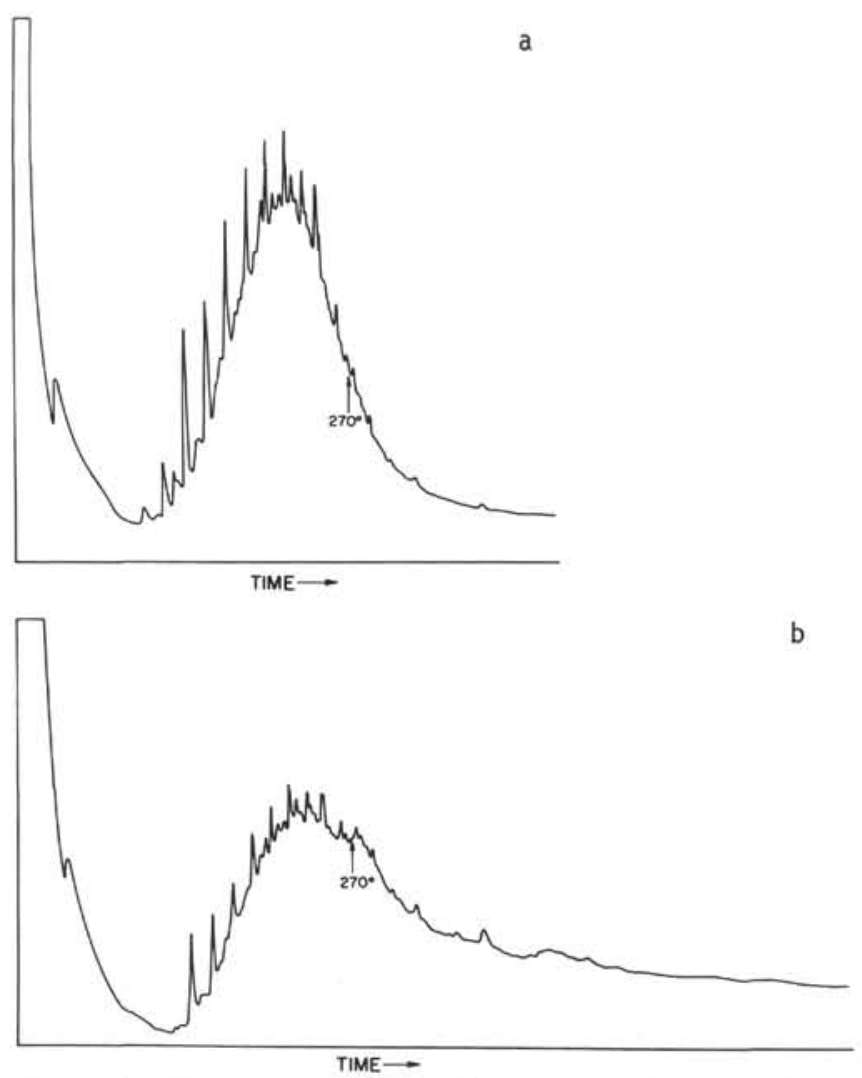

Figure 2. GC traces of two solvent extract fractions from Sample 217-1-3, 0-20 cm: (a) heptane-soluble material; (b) benzene and methanol-soluble material (GC conditions as cited in Figure 1).

Smith, D. H., Olsen, R. W., Walls, F. C., and Burlingame, A. L., 1971. Realtime organic mass spectrometry: LOGOS-a generalized laboratory system for high and low resolution, GC/MS and closed-loop applications: Anal. Chem., v. 43, p. 1796.

von der Borch, C. C., Sclater, J. G., Gartner, S., Jr., Hekinian, R., Johnson, D. A., McGowran, B., Pimm, A. C., Thompson, R. W., Veevers, J. J. and Waterman, L. S., 1972. Deep Sea Drilling Project Leg 22: Geotimes, v. 17, p. 15 .
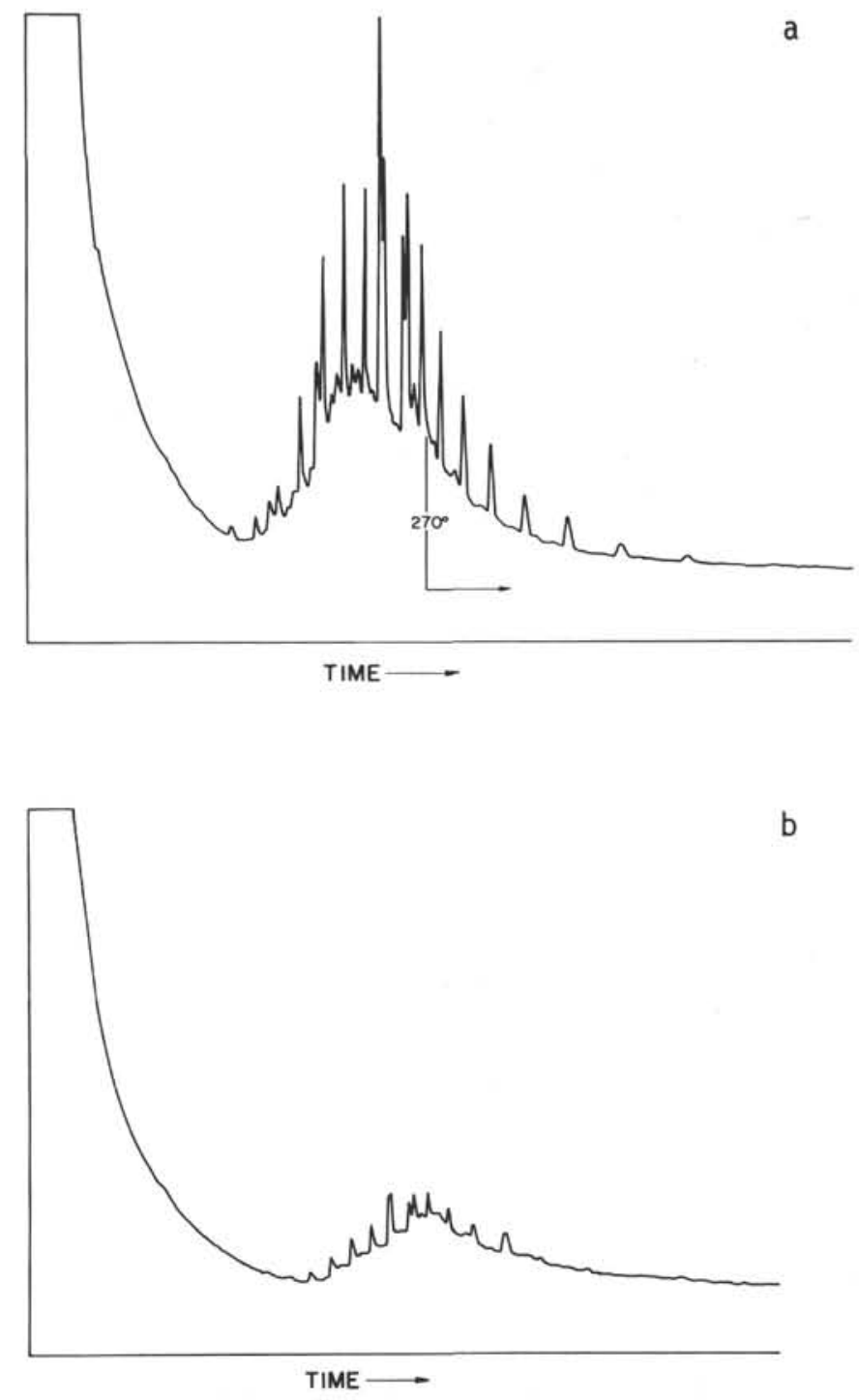

Figure 3. GC traces of two solvent extract fractions from Sample 217-6-5, 10-30 cm: (a) heptane-soluble material; (b) benzene and methanol-soluble material. (GC conditions as cited in Figure 1). 
PRELIMINARY ORGANIC GEOCHEMICAL ANALYSES
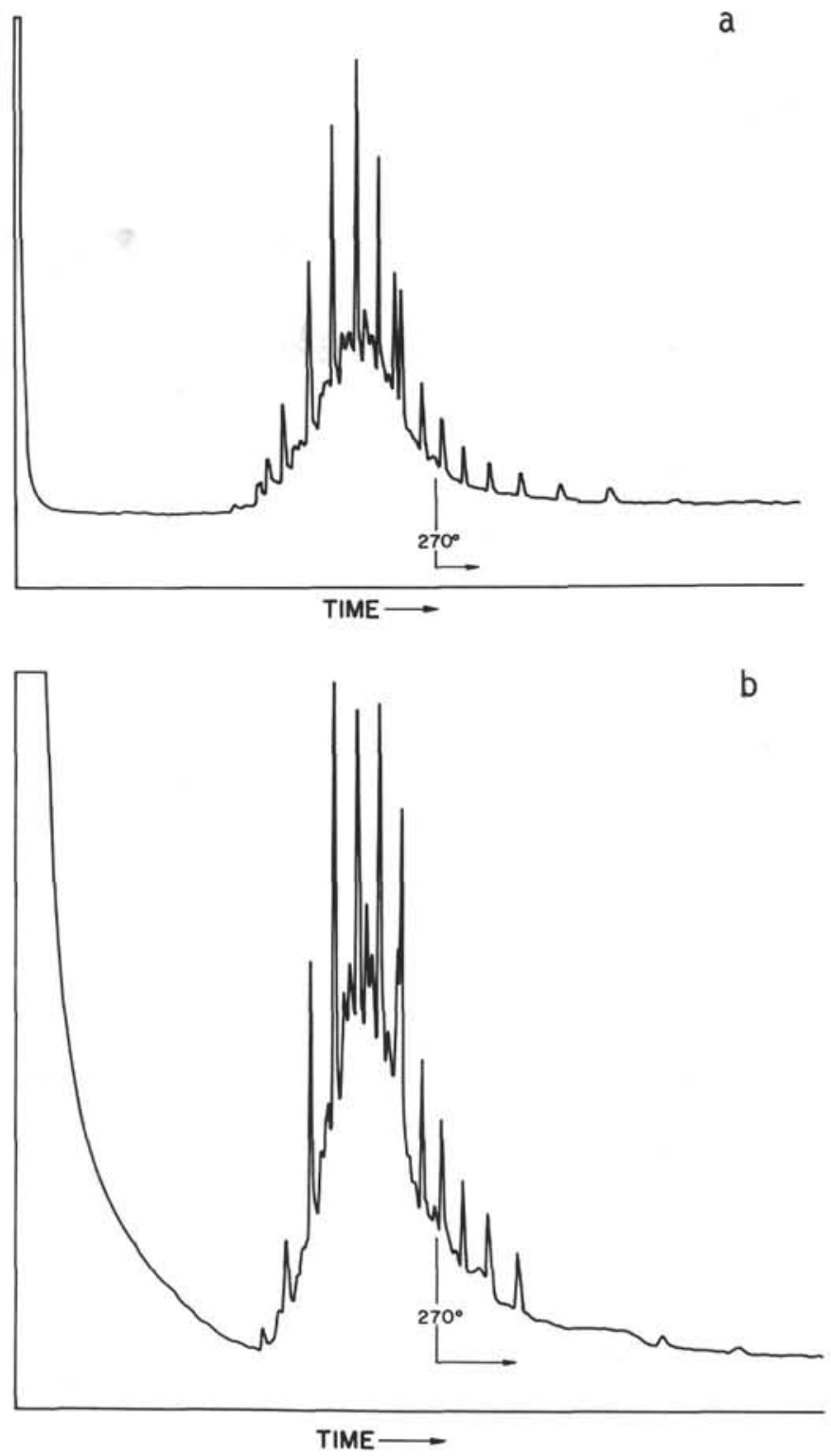

Figure 4. GC traces of two solvent extract fractions from Sample 217-14-4, 20-40 cm: (a) heptane-soluble material; (b) benzene and methanol-soluble material. (GC conditions as cited in Figure 1).

685 
B. R. SIMONEIT, A. L. BURLINGAME
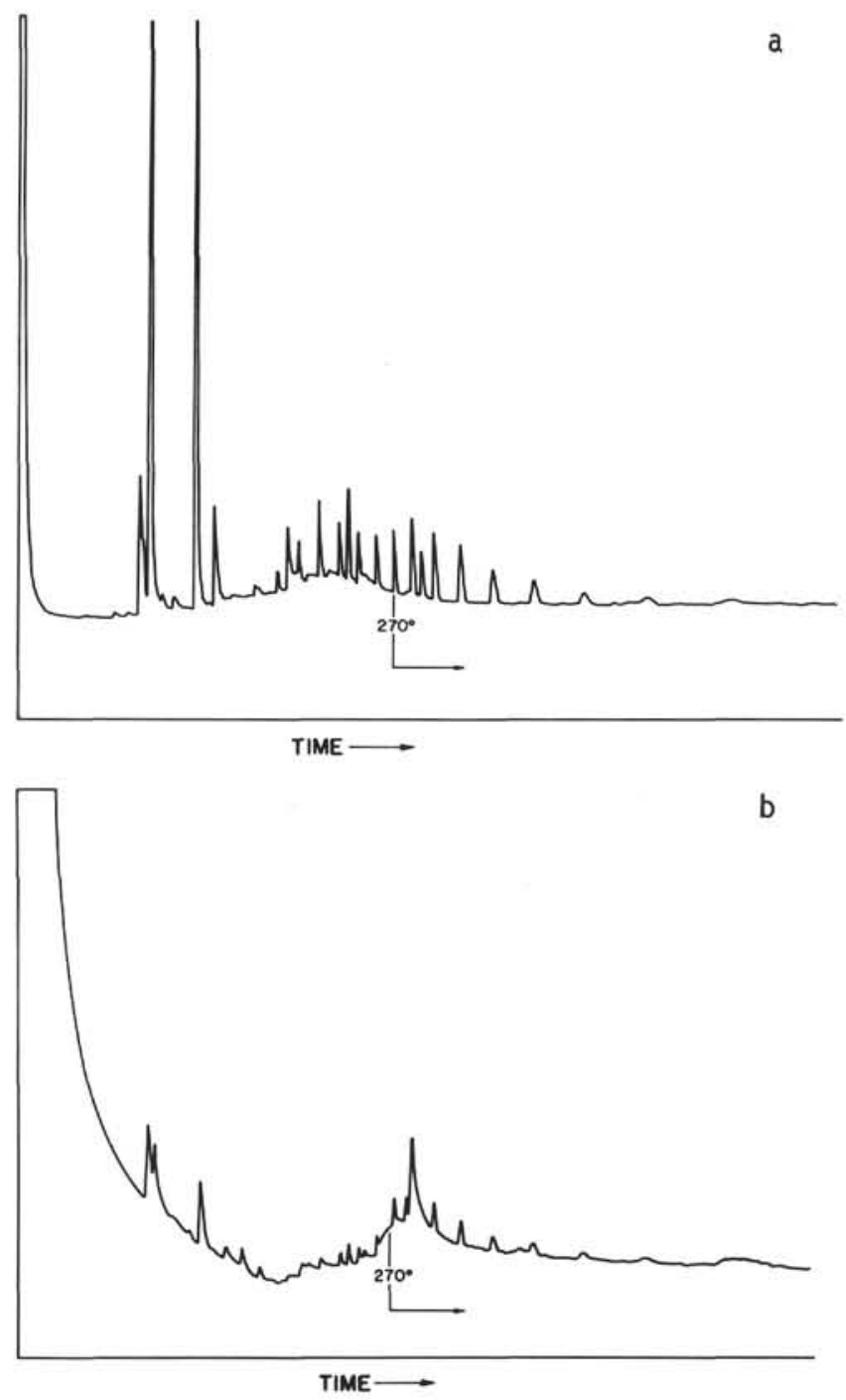

Figure 5. GC traces of two solvent extract fractions from Sample 217-30-3, 0-20 cm: (a) heptane-soluble material; (b) benzene and methanol-soluble material. (GC conditions as cited in Figure 1). 


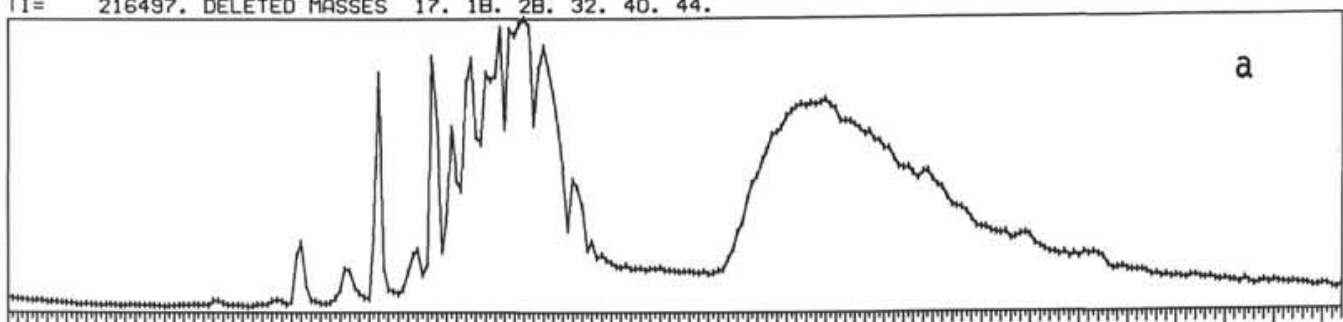

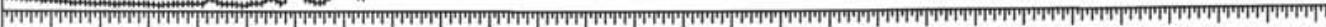

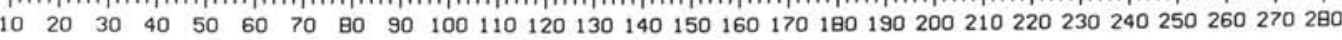
$T 1=39904$. SUM M/E $=57.0000$

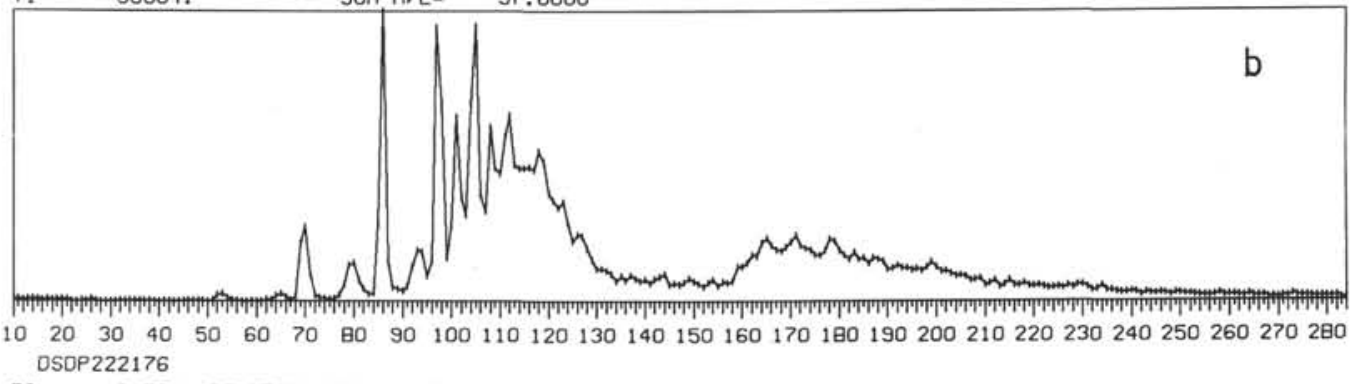

$\mathrm{TI}=\quad 91831$. DELETED MASSES 17. 1日. 2 28. 32.40 .44$.

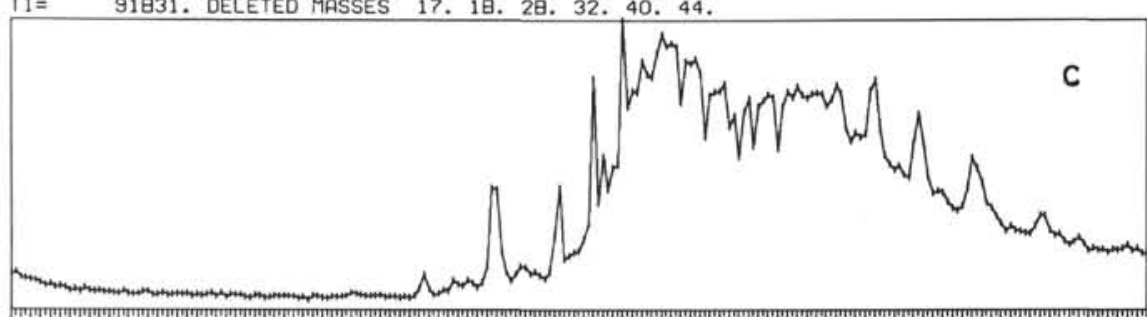

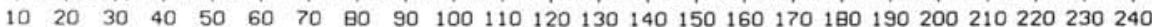

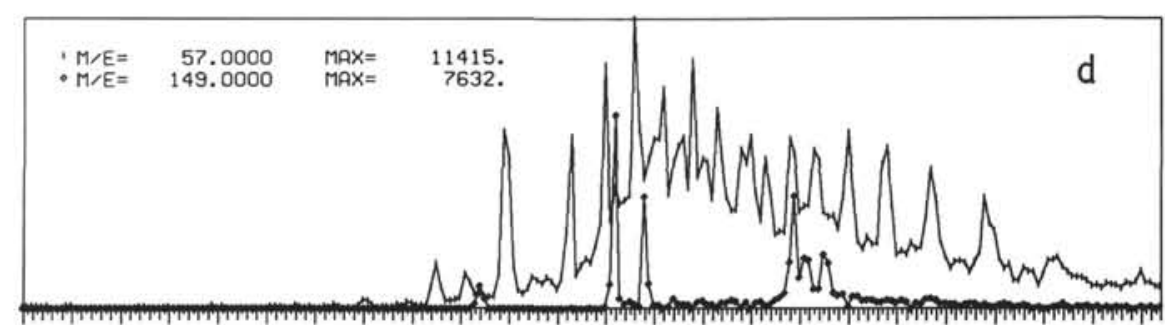

$10 \quad 20 \quad 30 \quad 40 \quad 50 \quad 60 \quad 70$ 80 $90 \quad 100110120130140150160170180190200210220230240$ DSDP22217144

$\mathrm{TI}=119067$. DELETED MASSES 17. 18. 2 1日. 32.40 .44$.

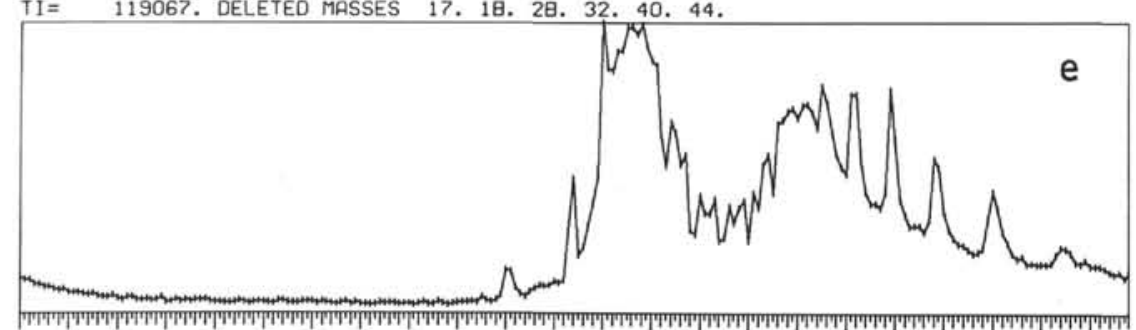

$10 \quad 20 \quad 30 \quad 40 \quad 50 \quad 60 \quad 70$ в0 $90 \quad 100110120130140150160170180190200210220230$

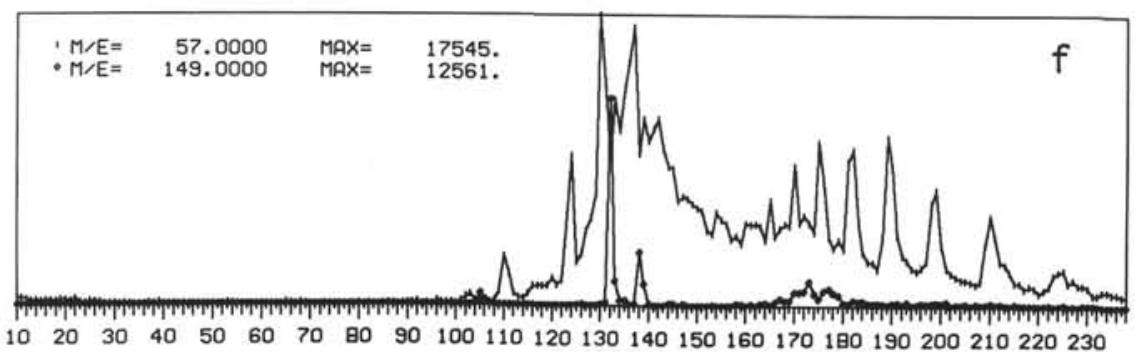

Figure 6. (a) Sample 217A-17-1, $83 \mathrm{~cm}$. Euhedral dolomite rhombs of Stage 3 (Figure 2) showing dolomite zone. Matrix . possibly cristobalite. Innermost calcite zone appears to be corroding dolomite core. Calcite zone retouched in black. (b) Sample 217A-17-1, $65 \mathrm{~cm}$. Euhedral dolomite rhombs of Stage 3 (Figure 2) showing corroded dolomite nuclei, followed by calcite-dolomite-calcite-dolomite zones. Slide stained, calcite zones retouched in black. (c) Sample 217A-17-1, $65 \mathrm{~cm}$. Similar to $(b)$. 
TI $=$ 11日564. DELETED MASSES 17. 1日. 28. 32. 40.44.

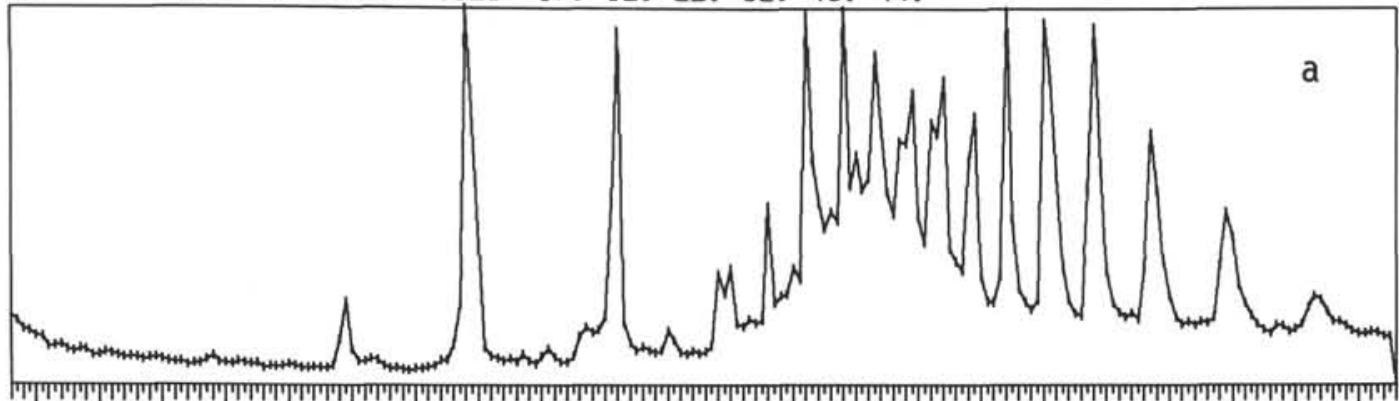

$20 \quad 30 \quad 40 \quad 50 \quad 60 \quad 70 \quad 80 \quad 90 \quad 100 \quad 110 \quad 120 \quad 130 \quad 140 \quad 150160170 \quad 180190200210220230$
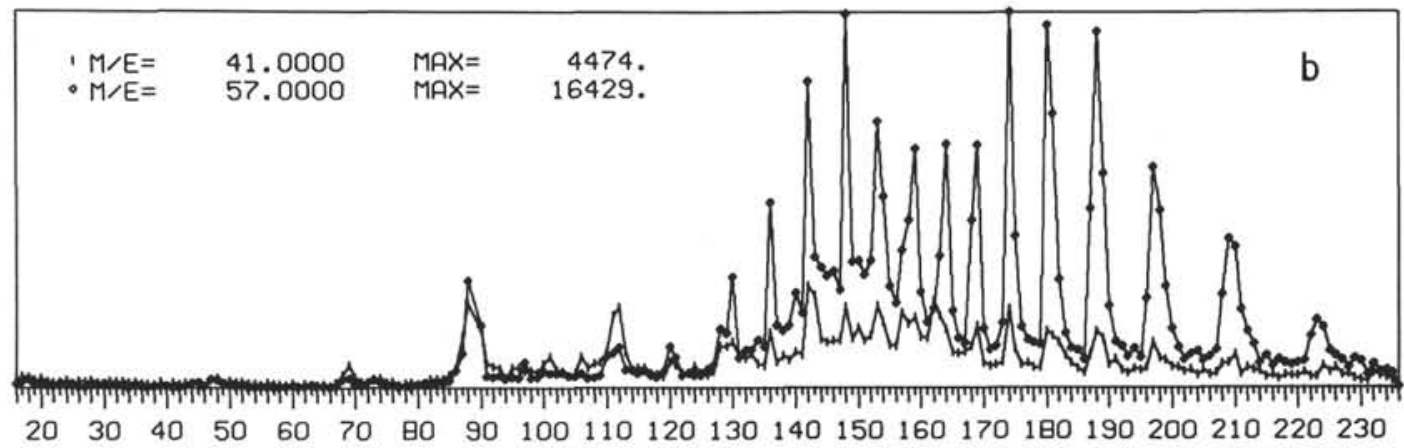

SCAN $112 \quad$ DSDP22217303

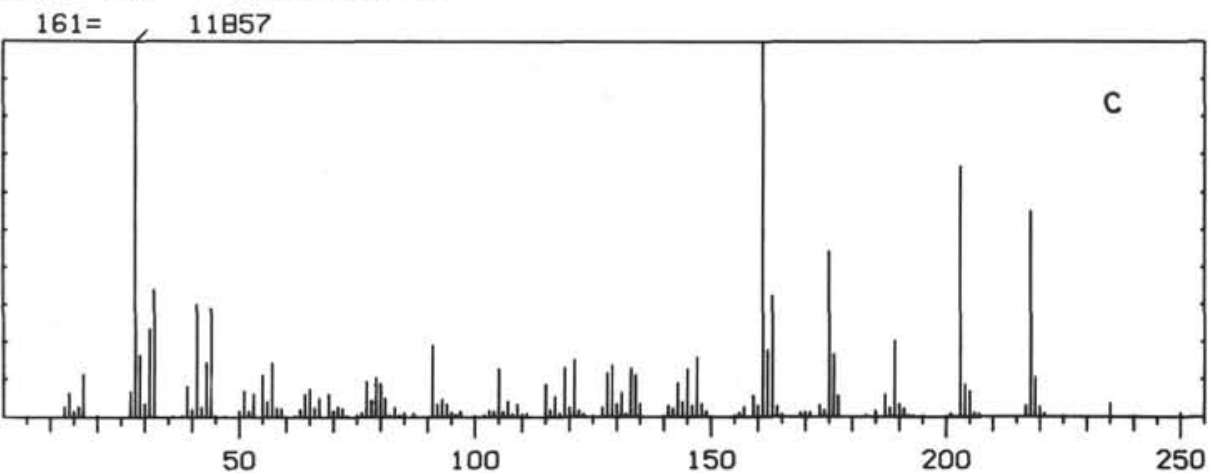

SCAN $129 \quad$ DSDP22217303

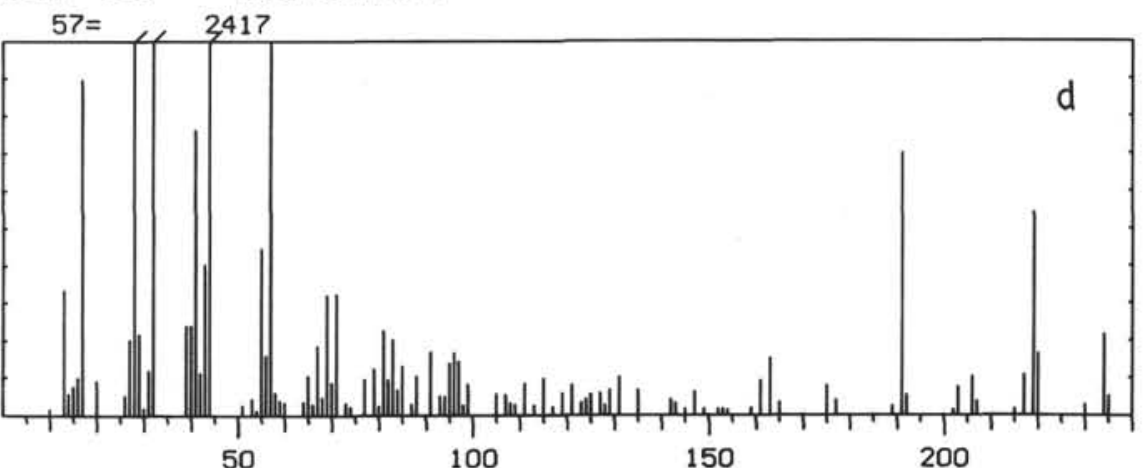

Figure 7. Selected GC/MS data for the total extract of Sample 217-30-3, 0-20 cm: (a) total ionization sum plot; (b) m/e 41 and 57 sum plot; (c) mass spectrum scan 112 (dipentylbenzene, MW 218); (d) mass spectrum scan 129 (unknown, MW 234). (GC conditions as cited in Figure $6)$. 


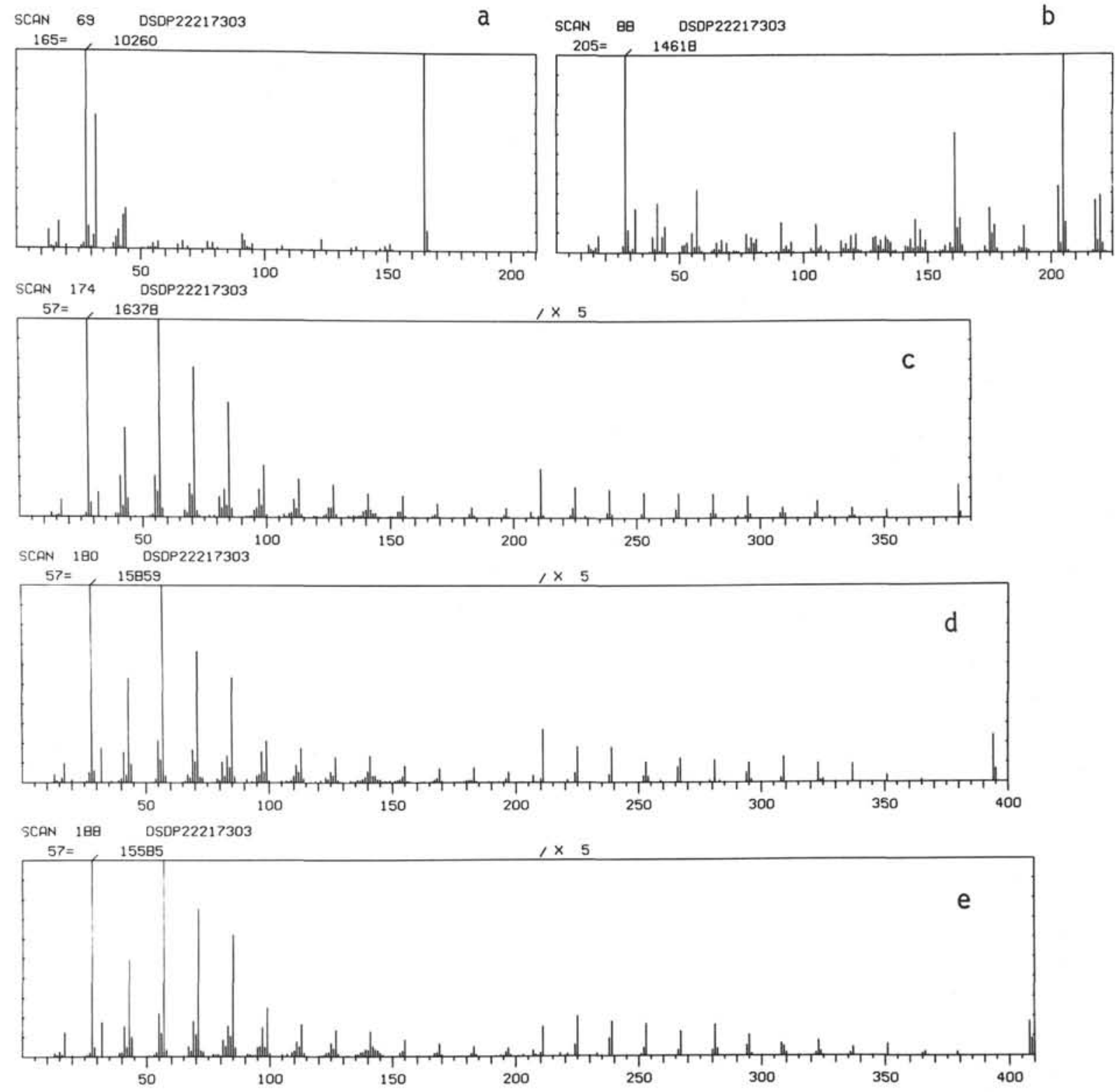

Figure 8. Selected GC/MS data for the total extract of Sample 217-30-3, 0-20 cm): (a) mass spectrum scan 69 (unknown, MW 165); (b) mass spectrum scan 88 (dipentylbenzene, $M W$ 218; unknown, $M W$ 220); (c) mass spectrum scan 174 (n-heptacosane, MW 380); (d) mass spectrum scan 180 (n-octacosane, MW 394); (e) mass spectrum scan 188 (n-nonacosane, MW 408). 
TABLE 2

Major Components of the Total Benzene-Methanol-Soluble Extracts from the Core Samples of Site 217, Determined by GC/MS

\begin{tabular}{|c|c|c|c|c|c|c|}
\hline \multirow[b]{3}{*}{ Compound } & & & \multicolumn{4}{|c|}{ Sample } \\
\hline & & & $\begin{array}{l}217-1-3 \\
0-20 \mathrm{~cm}\end{array}$ & $\begin{array}{l}217-6-5 \\
10-30 \mathrm{~cm}\end{array}$ & $\begin{array}{l}217-14-4, \\
20-40 \mathrm{~cm}\end{array}$ & $\begin{array}{l}217-30-3, \\
0-20 \mathrm{~cm}\end{array}$ \\
\hline & \multicolumn{2}{|c|}{$\begin{array}{l}\text { Composition and } \\
\text { Molecular Weight }\end{array}$} & $\begin{array}{l}\text { Spectrum Scan No. } \\
\text { (cf. Fig. 6a) }\end{array}$ & $\begin{array}{l}\text { Spectrum Scan No. } \\
\text { (cf. Fig. 6c) }\end{array}$ & $\begin{array}{l}\text { Spectrum Scan No. } \\
\text { (cf. Fig. 6e) }\end{array}$ & $\begin{array}{l}\text { Spectrum Scan No. } \\
\text { (cf. Fig. 7a) }\end{array}$ \\
\hline Tridecane & $\mathrm{C}_{13} \mathrm{H}_{28}$ & 184 & 52 & n.d. & n.d. & n.d. \\
\hline Tetradecane & $\mathrm{C}_{14} \mathrm{H}_{30}$ & 198 & 70 & 95 & n.d. & n.d. \\
\hline Pentadecane & $\mathrm{C}_{15} \mathrm{H}_{32}$ & 212 & 86 & 101 & n.d. & n.d. \\
\hline Diethyl phthalate ${ }^{a}$ & $\mathrm{C}_{12} \mathrm{H}_{14} \mathrm{O}_{4}$ & 222 & n.d. ${ }^{b}$ & 104 & 105 & n.d. \\
\hline$n$-Hexadecane & $\mathrm{C}_{16} \mathrm{H}_{34}$ & 226 & 97 & 109 & n.d. & 108 \\
\hline Dipentylbenzene & $\mathrm{C}_{16} \mathrm{H}_{26}$ & 218 & n.d. & n.d. & n.d. & 112 \\
\hline$n$-Heptadecane & $\mathrm{C}_{17} \mathrm{H}_{36}$ & 240 & 104 & 116 & 116 & 117 \\
\hline n-Octadecane & $\mathrm{C}_{18} \mathrm{H}_{38}$ & 254 & 112 & 123 & 123 & 124 \\
\hline$n$-Nonadecane & $\mathrm{C}_{19} \mathrm{H}_{40}$ & 268 & 119 & 130 & 130 & 130 \\
\hline Dibutyl phthalate ${ }^{a}$ & $\mathrm{C}_{16} \mathrm{H}_{22} \mathrm{O}_{4}$ & 278 & n.d. & 132,138 & 132,138 & n.d. \\
\hline iso-Eicosane & $\mathrm{C}_{20} \mathrm{H}_{42}$ & 282 & n.d. & n.d. & 135 & n.d. \\
\hline$n$-Eicosane & $\mathrm{C}_{20} \mathrm{H}_{42}$ & 282 & 126 & 136 & 137 & 136 \\
\hline iso-Heneicosane & $\mathrm{C}_{21} \mathrm{H}_{44}$ & 296 & n.d. & 140 & n.d. & n.d. \\
\hline$n$-Heneicosane & $\mathrm{C}_{21} \mathrm{H}_{44}$ & 296 & 134 & 142 & 142 & 142 \\
\hline$n$-Docosane & $\mathrm{C}_{22} \mathrm{H}_{46}$ & 310 & 141 & 148 & 147 & 148 \\
\hline$n$-Tricosane & $\mathrm{C}_{23} \mathrm{H}_{48}$ & 324 & 148 & 153 & 153 & 153 \\
\hline iso-Tetracosane & $\mathrm{C}_{24} \mathrm{H}_{50}$ & 338 & n.d. & 158 & n.d. & n.d. \\
\hline $\begin{array}{l}\text { Dioctyl 2,3-di- } \\
\text { methylsuccinate }\end{array}$ & $\mathrm{C}_{24} \mathrm{H}_{42} \mathrm{O}_{4}$ & 370 & 153 & 159 & 157 & 156 \\
\hline$n$-Tetracosane & $\mathrm{C}_{24} \mathrm{H}_{50}$ & 338 & 155 & 160 & 159 & 159 \\
\hline$n$-Pentacosane & $\mathrm{C}_{25} \mathrm{H}_{52}$ & 352 & 162 & 164 & 165 & 164 \\
\hline Dioctyl phthalate ${ }^{\mathrm{a}}$ & $\mathrm{C}_{24} \mathrm{H}_{38} \mathrm{O}_{4}$ & 390 & n.d. & 169 & 169 & n.d. \\
\hline$n$-Hexacosane & $\mathrm{C}_{26} \mathrm{H}_{54}$ & 366 & 170 & 168 & 170 & 169 \\
\hline$n$-Heptacosane & $\mathrm{C}_{27} \mathrm{H}_{56}$ & 380 & 178 & 173 & 175 & 174 \\
\hline n-Octacosane & $\mathrm{C}_{28} \mathrm{H}_{58}$ & 394 & 187 & 180 & 181 & 179 \\
\hline$n$-Nonacosane & $\mathrm{C}_{29} \mathrm{H}_{60}$ & 408 & 199 & 187 & 189 & 188 \\
\hline$n$-Triacontane & $\mathrm{C}_{30} \mathrm{H}_{62}$ & 422 & n.d. & 197 & 198 & 197 \\
\hline$n$-Hentriacontane & $\mathrm{C}_{31} \mathrm{H}_{64}$ & 436 & n.d. & 208 & 210 & 209 \\
\hline$n$-Dotriacontane & $\mathrm{C}_{32} \mathrm{H}_{66}$ & 450 & n.d. & 222 & 225 & 223 \\
\hline$n$-Tritriacontane & $\mathrm{C}_{33} \mathrm{H}_{68}$ & 464 & n.d. & 240 & n.d. & 238 \\
\hline$n$-Tetratriacontane & $\mathrm{C}_{34} \mathrm{H}_{70}$ & 478 & n.d. & 254 & n.d. & 255 \\
\hline
\end{tabular}

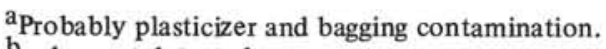

$b_{\text {n.d. }}$ not detected.

${ }^{c}$ Probably core tube contamination. 


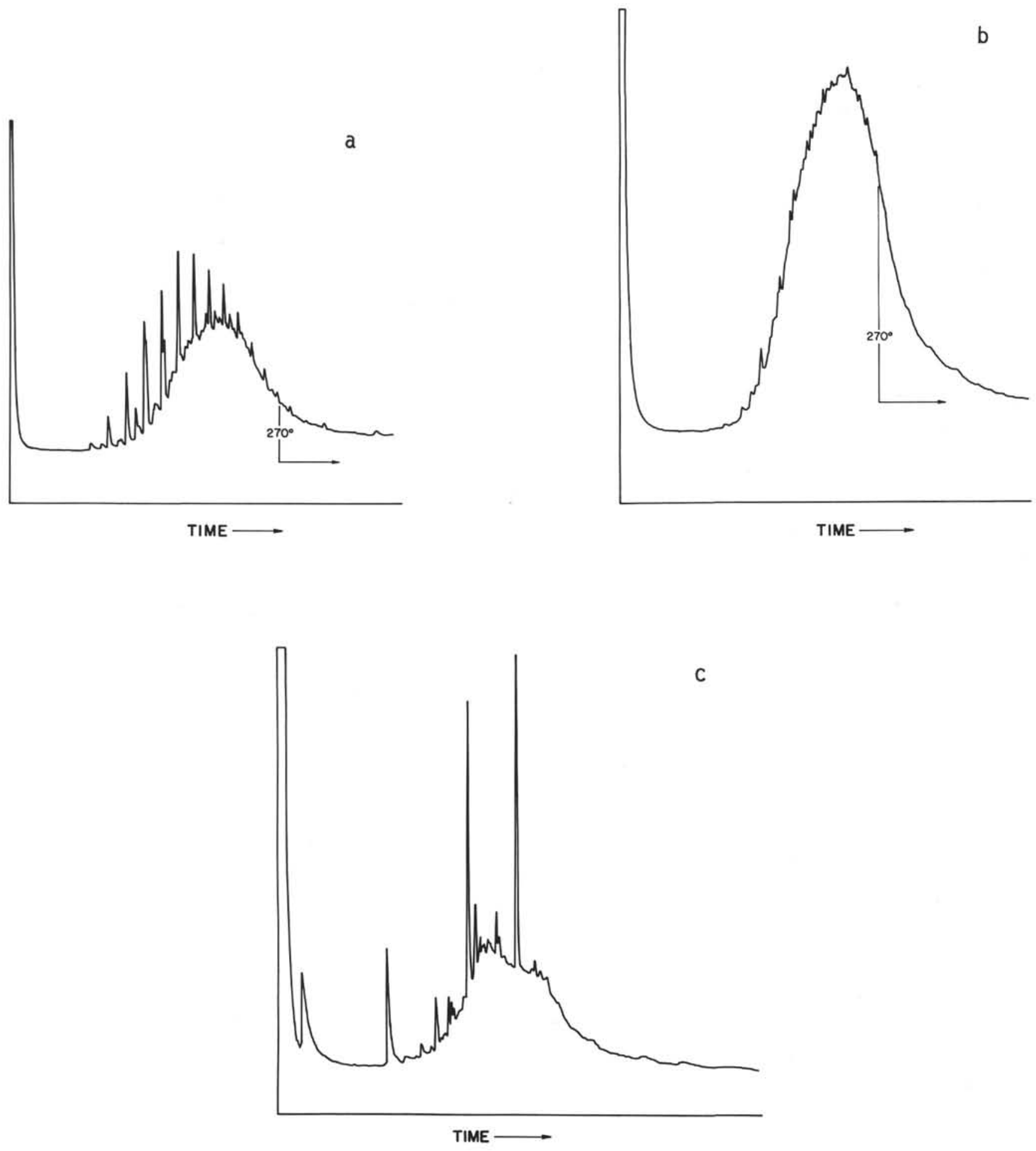

Figure 9. Representative GC traces of various fractions separated by silica gel chromatography of the extract from Sample 217-1-3, 0-20 cm: (a) fraction 1; (b) combined fractions 2, 3, and 4; (c) combined fractions 12 and 13. (GC conditions as cited in Figure 1). 
TABLE 3

Column Chromatographic Separation of the Total SolventSoluble Fractions from Sample $217-1-3,0-20 \mathrm{~cm}$

\begin{tabular}{|c|c|c|c|}
\hline Fraction & $\begin{array}{l}\text { Weight } \\
\text { (mg) }\end{array}$ & Eluent & Description \\
\hline 1 & 54 & $15 \mathrm{ml}$ heptane & Yellow liquid \\
\hline $2,3,4$ & 11 & $60 \mathrm{ml}$ heptane & Yellow oil \\
\hline $5,6,7$ & 1.2 & $90 \mathrm{ml}$ heptane & $\begin{array}{l}\text { Light green } \\
\text { oily solid }\end{array}$ \\
\hline 8,9 & 1.3 & $60 \mathrm{ml}$ heptane $/ 5 \%$ benzene & Yellow residue \\
\hline 10,11 & 4.7 & $60 \mathrm{ml}$ heptane $/ 20 \%$ benzene & Greenish solid \\
\hline 12,13 & 16.5 & $\begin{array}{l}60 \mathrm{ml} \text { benzene to benzene/ } \\
50 \% \text { methanol }\end{array}$ & $\begin{array}{l}\text { Dark green } \\
\text { residue }\end{array}$ \\
\hline
\end{tabular}
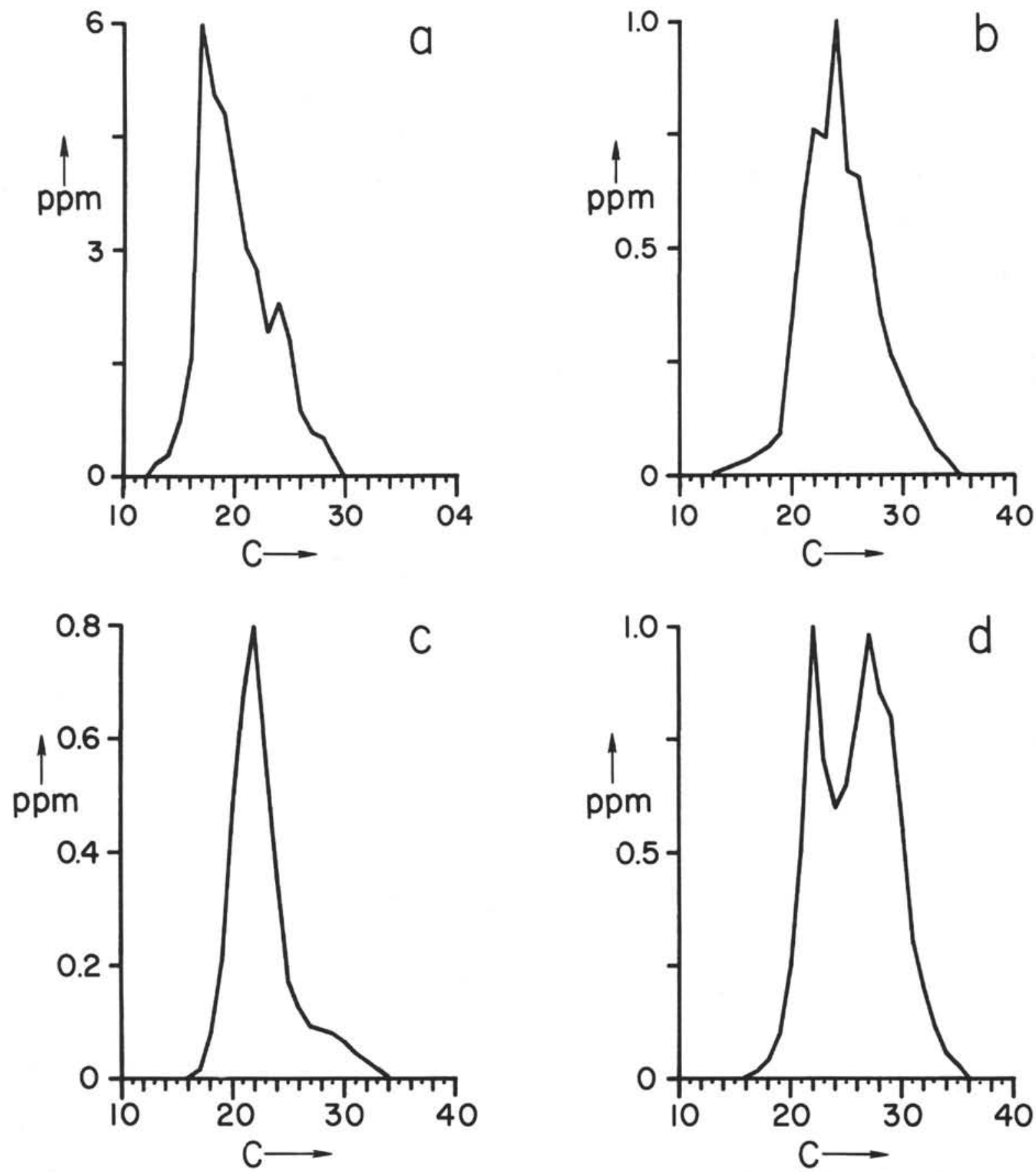

Figure 10. Normal alkane distribution histograms for the core samples from Site 217: (a) 217-1-3, 0-20 cm; (b) 217-6-5, 10-30 cm; (c) 21 7-14-4, 20-40 cm; (d) 217-30-3, 0-20 cm. (Concentrations are approximate as determined by $G C$ ). 